\title{
PERSPECTIVAS Y ACCIONES \\ DE CAMPESINOS DE ANTA-CUSCO \\ EN TORNO AL CAMBIO CLIMÁTICO
}

Doris León Gabriel

\section{Resumen}

La interrogante principal de este ensayo es conocer si las actuales variaciones climáticas globales afectan a los Andes de una manera tan extraordinaria que impiden su enfrentamiento con los métodos usuales que han tenido los campesinos en la sierra sur desde los milenios anteriores, o si actualmente se dan formas tan dramáticas de cambio que los campesinos se ven impedidos de seguir produciendo. En el Cusco en particular son especialmente las ONG las defensoras de la idea de un cambio climático provocado por los hombres, por lo que tratan de invocar en los campesinos acciones para estabilizar sus formas de producción. Sobre la percepción de los campesinos mismos hay poco conocimiento. Por ello, se buscará conocer si los campesinos tienen una percepción de un cambio dramático en las condiciones hídricas y de temperatura a las cuales no podrían responder con sus métodos largamente usados en los últimos milenios. Se aborda el tema del cambio climático en la vida cotidiana campesina de Cusco, el modo en que los campesinos perciben esta problemática y las ideas de las ONG al respecto. El trabajo de campo se realizó en el distrito de Izcuchaca, provincia de Anta en Cusco ${ }^{1}$.

Palabras clave: Cambio climático, Pampa de Anta-Cusco, estrategias campesinas de adaptación a variación climática, "Audiencias Climáticas", ONG.

Este ensayo se realizó para el curso de Temas en Antropología del semestre 2009-II de la E.A.P. de Antropología de la UNMSM. 


\section{Abstract}

The main question of this essay is whether the global climate changes of the last decades affect dramatically the Andes in ways that farmers from the southern highland can't confront this situation by using their usual agricultural methods developed since previous millennia, or currently there are such dramatic changes that farmers can't produce. Particularly in Cusco, NGOs are the institutions which defend the idea that there is a climate change produced by humans, so they encourage farmers to take actions in order to stabilize their ways of production. However, there is no good knowledge about what farmers think about it. Because of that, this essay tries to understand if farmers really perceive a dramatic change in water conditions and temperature that they can't confront with their usual methods. We'll know about the climate change in farmers' everyday life, the way they perceive this topic and NGOs' ideas about it. The fieldwork took place in the district of Izcuchaca, province Anta in Cusco.

Keywords: Climate change, Pampa de Anta-Cusco, farmers' adaptative strategies to climate change, "Climate Audience", NGO.

\section{Introducción}

Diversos cambios climáticos han afectado la agricultura mundial desde sus orígenes. Los Andes es un caso paradigmático de ello ya que su clima es sumamente frágil y se ve constantemente afectado por cambios. Por ejemplo, el fenómeno del Niño afecta las condiciones hídricas en los Andes y es por ello que ha sido de suma importancia y necesidad que los campesinos desarrollen estrategias para contrarrestar las precipitaciones pluviales inusitadas y sus consecuencias en la superficie en la cual producen sus alimentos; asimismo, han ingeniado formas complejas de utilización del suelo y de las aguas para los años de sequía. Estas adecuaciones a formas climáticas poco constantes son una parte de la versatilidad de la agricultura andina desde hace muchos milenios.

$\mathrm{La}$ interrogante principal de este ensayo es saber si las actuales variaciones climáticas globales afectan a los Andes de una manera tan extraordinaria para impedir el enfrentamiento con los métodos usuales que han tenido los campesinos en la sierra sur desde los milenios anteriores, o si actualmente se dan formas tan dramáticas de cambio que los campesinos se ven impedidos de seguir produciendo. En el Cusco, específicamente, son especialmente las ONG las defensoras de la idea de un cambio climático provocado por los hombres, por lo que tratan de invocar en los campesinos acciones para estabilizar sus formas de producción. Sobre la percepción de los campesinos mismos hay poco conocimiento. Por ello, se buscará conocer si los campesinos de Anta, Cusco, tienen una percepción de un cambio dramático en las condiciones hídricas y de temperatura a las cuales no podrían responder con sus métodos largamente usados en los últimos milenios.

El presente ensayo abordará el tema del cambio climático en la vida cotidiana campesina del Cusco, el modo en que los campesinos perciben esta problemática y 
las ideas de las ONG al respecto. La investigación busca responder a: ¿Cuáles son las perspectivas y acciones de los campesinos cusqueños frente al cambio climático? ¿De qué manera ven afectada su economía familiar? ¿Cómo las ONG ambientalistas han representado las visiones de estos campesinos? O, por el contrario, ¿ellas llevan el discurso de los ambientalistas globales al campo cusqueño? La investigación analiza los diversos discursos en los documentos como noticias, testimonios, pronunciamientos e información generada por las ONG sobre el tema; asimismo, se conversó con campesinos de Izcuchaca en Anta, personas involucradas en las organizaciones que abordan el tema del calentamiento global en Cusco y con un especialista en economía campesina.

\section{La problemática de los discursos sobre el cambio climático a nivel mundial}

La discusión sobre los cambios climáticos causados por el desarrollo industrial surge en zonas europeas a mediados del siglo xx como una bandera política de zonas con una gran densidad industrial y económica que visiblemente limita las posibilidades de las poblaciones de respirar saludablemente, disfrutar de un paisaje no contaminado por emisiones tóxicas de fábricas, etc. Este movimiento político adquiere una gran presencia con el accidente de Chernóbil en 1986, que evidenció a la población europea que efectivamente había una amenaza general en el desarrollo industrial y energético. La preocupación de la población se convirtió en una bandera política que rápidamente fue recogida por una serie de partidos políticos. Rápidamente este movimiento se centró en un cambio climático a nivel mundial que consistió en un cambio gradual de la temperatura media a nivel mundial. (Marcellesi 2008, BBC 2009).

Sin embargo, existía una discusión sobre la realidad de este llamado calentamiento global. En ella hay dos posiciones principales. La primera sostiene que en la historia de la Tierra siempre ha habido cambios climáticos y que la variación climática es solo una variación más en los cambios de temperatura global y por consiguiente también de las condiciones ecológicas en las diversas partes del mundo. La segunda posición sostiene que los actuales cambios climáticos y las variaciones en las condiciones naturales se dan por la intervención de las sociedades humanas, especialmente en lo que se refiere a la emisión de C02 de las sociedades industriales. Es el segundo grupo que trata de encontrar una solución política al problema del "calentamiento global" mediante conferencias internacionales que limitarían la emisión de los gases causantes de la variación climática condicionando el desarrollo industrial en cualquier país del mundo, exigiendo cambios en los procesos de producción industrial, en la infraestructura de transporte, y en general las condiciones de vida de los humanos en la Tierra.

No hay, al parecer, una posibilidad de decidir entre las dos posiciones a nivel científico. Los defensores de la idea de que los cambios climáticos se han dado desde tiempos inmemoriales en la tierra aducen que hasta el momento no es posible generar una simulación total de los cambios de temperatura en la superficie terrestre, ya 
que no hay aún una capacidad de observación suficiente de todos los factores que intervienen en la formación de los climas, ni existen programas de computación lo suficientemente complejos para una simulación que permita predecir cambios climáticos globales a mediano y largo plazo. Por otro lado, se muestran curvas de variación de climas y temperaturas en los últimos milenios, obtenidos ante todo por la investigación de sedimentos en los océanos y por secuencias de la glaciación en nevados y glaciares en Groenlandia y en la Antártida y otros indicadores. Los que sostienen que el cambio climático se debe a la intervención humana muestran ante todo cierto paralelismo entre el desarrollo de los procesos industriales desde el siglo XIX y una elevación de la temperatura global, una deglaciación en los Alpes, los Andes, la Antártida y especialmente en el Ártico durante los dos últimos siglos.

Si bien esta discusión nunca terminó en una demostración clara de cuáles eran los orígenes del cambio climático, se produjo un consenso político a nivel mundial especialmente porque en los últimos decenios del siglo xx hubo un aumento paulatino de la temperatura media a nivel mundial. Parece que este cambio de temperatura ya no se prolongó en los últimos años como lo señala un artículo de la BBC publicado en octubre de este año, en el cual se indica que el año más cálido registrado en los últimos años fue 1998, es decir, la temperatura media de la tierra no ha aumentado en 11 años a pesar de que sí se han incrementado las emisiones de CO2. Los científicos escépticos frente al calentamiento global afirman que hay ciclos naturales sobre los cuales no tenemos control, que determinan qué tan elevada es la temperatura del planeta. Ellos sostienen que el $98 \%$ del calor de la tierra proviene del sol².

No obstante, los discursos sobre el calentamiento global se han convertido en una verdad política aceptada que tiene como consecuencia una utilización de los recursos de los estados y diversas organizaciones para limitar la emisión de gases de $\mathrm{CO} 2$ y frenar de esta forma el aumento de la temperatura media que se proyectaba linealmente al futuro. Esta preocupación política a nivel mundial llevó a que se destinara recursos a la propagación de acciones, también en países como el Perú para frenar a lo que se consideraba como amenazante para el desarrollo futuro de toda la humanidad. Así que las ONG que operan en el Perú incluyeron una concientización sobre esta temática en sus agendas.

\section{La situación en el Perú}

Si bien en el Perú no hay estudios fidedignos sobre los efectos que tendría un calentamiento general de la tierra en las condiciones climáticas de la naturaleza muy variada, la agenda política de las ONG asumió que este también tendría influencia sobre las condiciones de vida en el Perú, especialmente en cuanto a la disponibilidad de recursos hídricos para la población creciente. Las ONG tomaron especialmente la reducción del tamaño de los glaciares como indicador de que en el futuro se

\footnotetext{
2 En: What happened to global warming? Por Paul Hudson. BBC News, 9 de octubre 2009. http://news.bbc.co.uk/2/hi/8299079.stm
} 
producirían problemas serios en el suministro de agua para la agricultura en el Perú y se asignaron como una de sus tareas la "concientización" de la población campesina sobre los efectos que se esperaba por la desaparición de flujos de agua que se producirían a partir de una mayor evaporación de agua, la desaparición de los glaciares y otros efectos parecidos de lo que se asumía era una consecuencia del calentamiento global en toda la superficie terrestre. Quizá se tenga que mencionar aquí que no hay estimados fidedignos sobre las consecuencias que un calentamiento global tendría sobre las condiciones climáticas en las regiones naturales muy diversificados del país.

\section{Situación de la agricultura en la Pampa de Anta y la comparación con el Altiplano circunlacustre: métodos campesinos de adaptación a las variaciones climáticas}

La observación e información obtenida sobre las percepciones campesinas en cuanto al llamado calentamiento global giran en torno a la Pampa Anta y particularmente al distrito de Izcuchaca que fue donde se realizó un breve trabajo de campo.

Según información consignada en el Plan Vial participativo de la provincia de Anta, el uso actual del suelo de esta provincia está condicionado por las características climáticas de cada región. La Pampa de Anta es el área que concentra la mayor actividad pecuaria de la provincia, complementada por cultivos agrícolas, de maíz, cebada, trigo, habas, que a su vez sirven como insumo o pastura para la alimentación de los vacunos.

La cédula de cultivos en la provincia de Anta es muy diversificada y está condicionada principalmente por el clima, las zonas de vida y el tipo de suelos. Predominan los cultivos de papa, maíz, cebada, trigo, haba, quinua, olluco, cebolla, zapallo y frijol. Estos últimos principalmente en los distritos de Mollepata y Limatambo.

La situación de la Pampa de Anta resulta especial debido al ingreso fuerte y constante de masas de aire procedentes de la Amazonía que producen en ella precipitaciones pluviales constantes y de envergadura. La zona comprendida entre el valle del Urubamba y el valle del Cuzco presenta precipitaciones pluviales fuertes. Esto resulta visible no solo por la gran cantidad de riachuelos que cruzan la zona — desde una altura de 3800 metros - hacia los valles del Cuzco y el valle de Urubamba, sino en la misma Pampa se han formado grandes lagunas que tienen una importancia especial para el manejo de irrigación de la Pampa. (Smith, 1981)

Para entender esto hay que ver que la Pampa de Anta no es uniforme en cuanto a las formas de utilización del suelo, sino hay formas múltiples de acomodamiento de la superficie para el uso agrícola ganadero. Por una parte hay especialmente en las zonas relativamente altas una agricultura de secano que se diferencia de otras zonas de agricultura de secano por la mayor presencia de lluvias de la zona y también porque la altura media de toda la pampa es relativamente baja (entre 3300 y 3800 metros). Toda la Pampa, a diferencia del Altiplano pertenece más bien a la zona Suni y Quechua en las categorías de Pulgar Vidal y en ningún punto alcanza las condiciones de la Puna que en otras zonas caracteriza los Andes Centrales del Sur. De ahí que hay 
buenas condiciones para la ganadería con animales que en este caso es una ganadería de vacunos y en parte de ganado lanar (ovejas) que pastean en las zonas altas en las zonas dejadas en descanso. Los descansos son relativamente breves porque la altura menor hace que los pastos crezcan en mayor cantidad. Así que hay en las tierras de secano una alternancia frecuente entre el uso agrícola y el ganadero. Esto, sin embargo, no impide que la ganadería alcance una envergadura bastante grande, ya que los animales también pastean en las tierras que tienen otros tipos de cultivo entre los rastrojos que quedan en la superficie agrícola después de las cosechas ${ }^{3}$.

Más importancia tiene la agricultura con irrigación. Como la pampa esta ligeramente inclinada hacia el valle del Urubamba y hacia el valle del Cuzco hay múltiples canales de irrigación que surcan los terrenos y que permiten un uso agrícola prolongado de los terrenos. El suministro de agua se origina en lagos relativamente grandes como el de Huaypo y el de Puray y otros de menor tamaño. Por lo general son lagos que se han formado de manera natural entre las colinas del terreno ligeramente ondulado de la Pampa. Lo que hace especial estas lagunas es que no solo se nutren de las lluvias y de los riachuelos en la época húmeda, sino al mismo tiempo sirven de reserva de agua para la irrigación en la pampa y en las quebradas que se han formado hacia el valle del Cuzco y del valle del Urubamba. En estas quebradas normalmente se trabaja con terrazas irrigadas. El agua para la irrigación nace de fuentes en las pendientes de la Pampa y en canales derivados de las lagunas (Anta 2006).

Una forma excepcional de uso de técnicas agrícolas la observamos en Maras, que se encuentra en la cabecera de una quebrada formada en la pendiente pronunciada hacia el Valle del Urubamba. Es que parece que el agua subterránea en la zona de Maras pasa por depósitos de sal y llega a la superficie en un manantial del cual brota agua salada. La gente de Maras utiliza las terrazas que en este tipo de quebradas son andenes de sembrío de maíz y otros frutos agrícolas, para un fin particular. Han convertido cada "chacra" en los andenes en una poza, a la cual pequeños canales conducen el agua salada que discurre por un canal en la parte superior de la quebrada. El acceso del agua a cada "chacra" es regulado por minúsculas compuertas que se abren y se cierran con telas enrolladas. Estas compuertas se abren repetidamente en la época seca para llenar la "chacra" con agua salada. Ya cerrada la compuerta el agua se evapora y se forma una capa de sal en ella (Orlave en Morlon, 1996). Repitiendo el mismo procedimiento en la época seca de acuerdo a la velocidad de evaporación cada chacra resulta al final de ella un depósito de sal que hoy en día se cosecha en costales de plástico que son vendidos como sal yodada. Parece que esta utilización de una técnica agrícola para fines de producción de sal data de mucho tiempo atrás. Las casas en el pueblo de Maras que datan de la época colonial muestran entradas lujosas construidas de arcos de piedra con los blasones de sus habitantes, que no pudimos observar en ninguno de los otros pueblos. Así que es de suponer que en la época colonial, e incluso en la época inca y anteriores, Maras debe haber sido una fuente importante de exportación de sal especialmente hacia la selva, ya que ahí mismo pasa el camino

\footnotetext{
$3 \quad$ Jurgen Golte (Comunicación personal, 16 de noviembre 2009).
} 
incaico que conduce hacia la Convención y también el camino incaico que corre hacia Machu Picchu y sigue a otras ruinas incaicas que están más adentradas a la selva. Desgraciadamente no hemos podido ubicar ninguna fuente bibliográfica que describiría este sistema muy particular de producción de sal y menos aun fuentes etnohistóricas que podrían echar una luz sobre esta utilización particular de una tecnología agrícola con fines de producir un bien preciado en el intercambio entre tierras altas y tierras bajas en la época colonial, ni tampoco logramos información sobre investigaciones arqueológicas que podrían echar una luz sobre la antigüedad del sistema, a pesar de que averiguamos entre los arqueólogos de la UNSAAC sobre ello.

Pero con el ejemplo de Maras está descrita también la forma que tiene el mismo sistema con agua dulce. La precipitación pluvial excepcionalmente abundante de la zona alimenta una gran cantidad de puquiales y fuentes de agua durante una buena parte del año que permiten una agricultura en la andenería que hay en las quebradas hacia el valle del Urubamba y hacia el valle del Cuzco. La presencia de lagunas a su vez ofrece una reserva de agua en las épocas del año en que el agua de los manantiales empieza a disminuir.

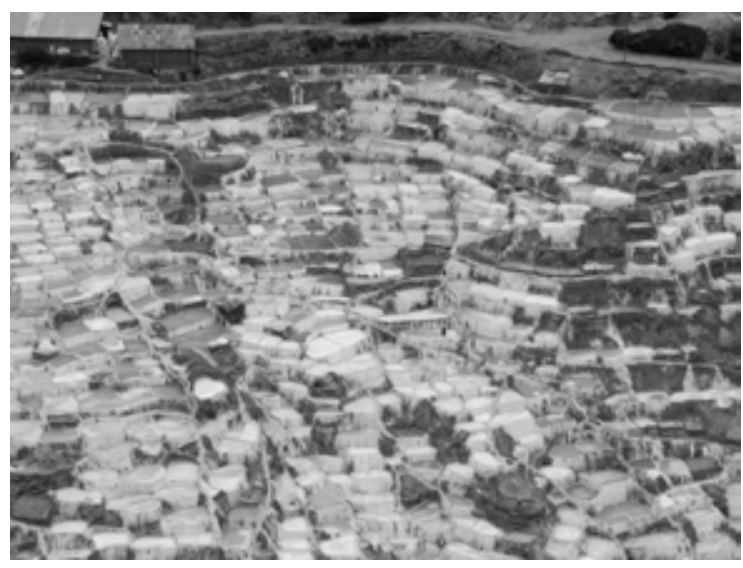

Andenerías en las salinas de Maras, Cusco. Noviembre del $2009^{4}$

Esto nos conduce a un tercer sistema de uso agrícola que es descrito en otras fuentes para el lago Titicaca (Bergman y Stroud Kussner 2000). El lago Titicaca tiene una variación fuerte de agua según el cambio climático en los Andes Centrales del Sur de acuerdo a periodos prolongados de sequía y calor que se alternan en ciclos que pueden durar por una serie de años. Se ha visto diferencias del nivel del lago que alcanzan diez metros entre los niveles más bajos al final de periodos de sequía prolongada y otros de periodos de lluvias más abundantes en la cuenca. El nivel superior está marcado por el Desaguadero que conduce las aguas sobrantes hacia el lago Poopó en Bolivia y los salares que se encuentran más al sur. Las riberas del lago Titicaca tienen por lo general una pendiente suave que muestra chacras orientadas hacia la ribera del agua que se prolongan en totorales que ya se encuentran en el agua donde se puede observar a ganado vacuno que esta pasteando la totora.

\footnotetext{
4 Todas las fotografías presentadas en este trabajo fueron tomadas por la autora.
} 


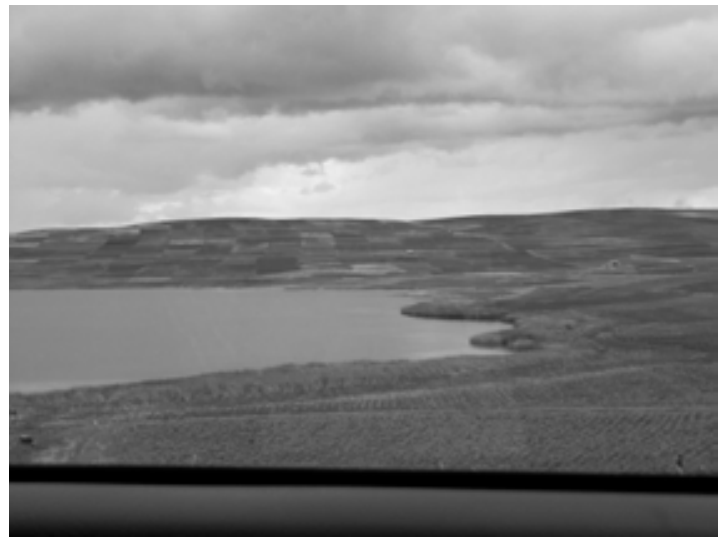
agua del lago en las épocas de sequia prolongada las franjas de chacras al borde del lago simplemente son extendidos hacia el terreno que antes estaba ocupado por los totorales. Es decir, en la época de sequía prolongada crece la superficie cerca del lago porque mantiene una humedad del suelo suficiente para el cultivo.

Estas tierras que se gana en la época de sequía son especialmente fértiles por los nutrientes dejados en el suelo en los totorales y también porque la cercanía del lago equilibra la temperatura nocturna. Esto es importante porque en la cercanía del lago Titicaca la cantidad de días con helada nocturna alcanza alrededor de 210 días al año. Estas heladas limitan las posibilidades del cultivo ya que las heladas nocturnas queman el follaje de las plantas.

Ahora, en la zona del Titicaca se ha ampliado los beneficios de la agricultura en la zona limítrofe del lago mediante los "waru waru" o camellones (Morlon 1996), que son chacras elevadas, construidas artificialmente, separadas por canales de agua que no solo sirven para equilibrar la temperatura nocturna, sino también fuentes de abono. Es que en los canales entre las chacras crecen rápidamente algas que se echa encima de la las chacras elevadas y que enriquecen los nutrientes que aumentan la productividad en las chacras elevadas. Estas chacras elevadas en la zona limítrofe del lago tienen especial importancia para los cultivos de tubérculos, ya que estos se pudrirían si fueran cultivados en los suelos húmedos dejados por el lago cuando el nivel del lago baja. (Earls 2009; Bergman y Stroud Kussner 2000; Flores Ochoa 1996)

Este sistema de alternancia entre temporadas prolongadas de sequía y otras de mayor abundancia de lluvias parecen importantes para la discusión del tema de este ensayo, ya que muestran que los campesinos del Altiplano han desarrollado sistemas agrícolas que prevén épocas de calentamiento y sequia por un lado y lluvias más abundantes por otro lado, pues cuando éstos se dan los campesinos pueden recurrir con más intensidad al cultivo de secano en las superficies planas del Altiplano y las laderas de los cerros en las inmediaciones del lago. Pierre Morlon ya ha señalado que para la reducción de los riesgos climáticos los campesinos de la zona del Altiplano recurren a diversos tipos de acondicionamientos como las infraestructuras de riego, árboles y muros: las campiñas, andenes, camellones, qochas, etc.

Esto nos muestra de cierto modo que campesinos de la zona norte del altiplano están plenamente conscientes de las alternancias climáticas prolongadas. Ello resulta notorio por el sistema de "qochas", lagunas artificiales que se encuentran en 
toda la zona norte del altiplano. Las qochas son estanques artificiales alimentados por las lluvias, que son conservadas allí durante la estación seca, y evacuadas antes del barbecho del suelo y la siembra. Forman redes unidas por canales que permiten transvasar el agua de una a otra, o derivarla hacia los ríos (Flores Ochoa, Paz Flores y Rozas 1996). También existen lagunas que se forman por la deglaciación de los glaciares de las cumbres del Nudo de Vilcanota, especialmente por el macizo del Ausangate. En épocas de sequía prolongada estas qochas son utilizadas al igual como las tierras que deja el lago cuando baja su nivel de agua. En los bordes la gente va cultivando mientras retrocede lentamente el nivel del agua, incluso cuando el agua ha desaparecido por completo el fondo de la laguna sirve para obtener una cosecha en las tierras húmedas. El sistema de qochas de esta forma es una expresión de que los campesinos andinos están plenamente conscientes de las variaciones prolongadas de las condiciones hídricas conforme a variaciones climáticas prolongadas en su hábitat.

Estos mismos tipos de sistemas de adaptación a los cambios climáticos, que generalmente son descritos para el Altiplano, los observamos de la misma forma en la Pampa de Anta. Justamente en el trabajo de Florez Ochoa y Paz Flores sobre qochas hacen mención por referencia de colegas a la existencia de formas semejantes en otras partes de la cuenca del lago Titicaca como en la llanura de Anta. Efectivamente, pudimos confirmar su existencia en la zona. Especialmente la ocupación de los suelos dejados abiertos con el retroceso de las lagunas en épocas de sequía practicada por los campesinos en las riberas del lago Titicaca y también en las "qochas" se repite alrededor de las lagunas en la Pampa de Anta. Así que se puede postular que los habitantes de esta zona, al igual como sus vecinos más al sur, muestran en sus técnicas agrícolas una adaptación a cambios climáticos de larga duración, como el actual "calentamiento global".

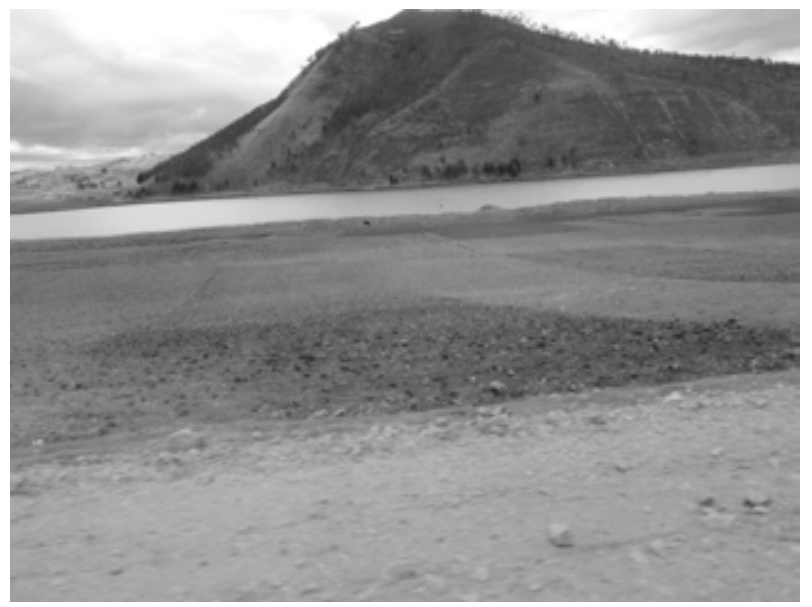

Cultivos alrededor de la laguna Poroy en Anta, Cusco. Noviembre del 2009

Sin embargo, pudimos observar y obtener información en nuestras conversaciones con campesinos y comerciantes de verduras del mercado de Izcuchaca dos respuestas más que muestran la elasticidad de los sistemas productivos. Según los agricultores de la zona el aumento de la temperatura media ha producido como efecto que crezcan y den frutos plantas que en las épocas anteriores no se producían. Un informante nos contó de una higuera que durante el tiempo que él la había observado nunca había dado fruto; 
sin embargo, la temperatura media más alta de los últimos decenios produjo que la higuera que vegetaba cerca de su casa no solo desarrollaba un follaje más denso, sino se produjo un florecimiento y finalmente el crecimiento de higos. De la misma forma otros campesinos nos informaron que habían sustituido variantes de especies cultivadas por otras más adecuadas a las temperaturas más elevadas, por ejemplo nos contaban que ya no se cultivaban ciertas variedades de papa en la zona pero que en su defecto se cultivaban otras especies de la misma y que incluso había ONG que promovían el cultivo de diferentes tipos de papas nativas. De este modo, ante la pregunta sobre la reducción de las cosechas de papa una señora nos contestó que todo lo contrario, es decir, que había más papas por las nuevas variedades cultivadas.

Por otro lado, se habían introducido cebollas en chacras que antes no resultaban aptas para este cultivo. Esto nos fue confirmado por las vendedoras en el mercado de Izcuchaca que nos hablaban de una sobreoferta de cebollas en los últimos años. Así que pudimos constatar un cambio de cultivos ligado con los cambios de temperatura y no tanto con los cambios de la humedad producidos por un "calentamiento".

Esta observación vale también para la productividad de la chacra. Los campesinos se mostraban conscientes de que una temperatura media más elevada generaba un mayor crecimiento en las plantas cultivadas, especialmente las hortalizas, entonces nos mencionaban por ejemplo coles, calabazas, coliflor, hierbas aromáticas como el huacatay y perejil, y también las papas.

En resumen, observamos que los campesinos percibían la variación climática de los últimos decenios más por el lado de la variación de temperatura que los beneficiaba, y menos por el lado de la falta de humedad necesaria para el cultivo. Al preguntarles por el aumento de la temperatura como algo notorio y grave que afectaba

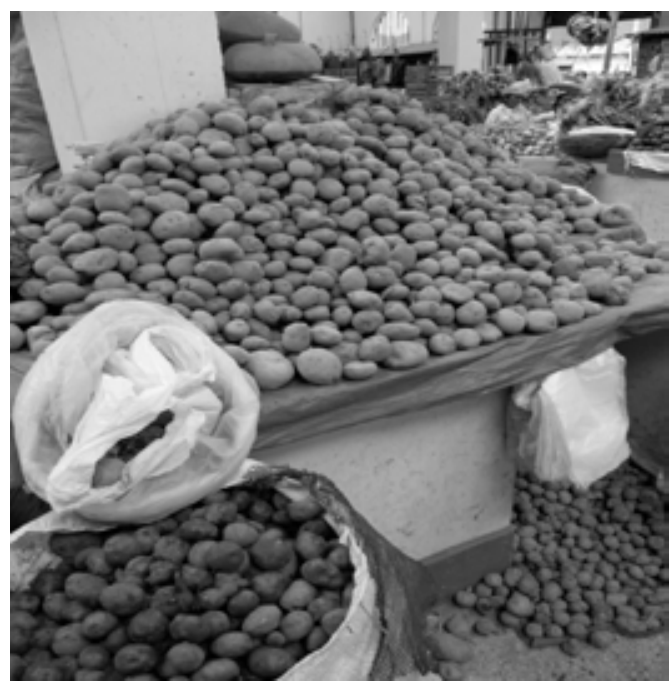

sus cosechas la mayoría contestaba de que algunas cosechas se habían reducido pero que la variación de la producción era algo constante en el tiempo, es decir, los cambios con altas y bajas en la producción de los diferentes alimentos agrícolas es algo que siempre ocurre: "A veces hay y a veces no hay".

Ahora bien, en cuanto a la variación de la temperatura como un posible beneficio para los cultivos, esto quizá se deba a las condiciones especiales de la Pampa de Anta en cuanto a la posibilidad de ingreso de los aires húmedos provenientes de la Amazonía. Era visible que durante nuestra estadía en la segunda mitad de noviembre, es decir, en una época en la cual por lo normal en la sierra empieza sin mucha fuerza el inicio de la época húmeda 
con la precipitación pluvial, cada día estaba marcado por una mañana ligeramente soleada, mientras en las tardes se producían lluvias de regular intensidad, y en algunos casos de mucha fuerza, que convertían por ejemplo las calles del Cuzco en pequeños riachuelos.

Algo más que apoya nuestras afirmaciones es la información sobre la producción agrícola registrada en el Plan Vial participativo de la provincia de Anta del año 2006, que señala que:

En el último quinquenio la producción agrícola de la provincia de Anta se ha incrementado de 22986 a 55008 toneladas, lo cual en términos de valor bruto de la producción (VBP) significa un incremento de 13,7 a 25,6 millones de soles. Los productos que generan el mayor valor bruto de la producción agrícola son: papa $(35 \%)$, trigo $(8 \%)$, maíz $(7 \%)$, cebada $(6 \%)$ y haba $(5 \%)$. (El énfasis es mío) ${ }^{5}$.

Entonces observamos que a pesar de que se habla mucho de los graves problemas que el calentamiento global causa a la agricultura, vemos que esta información señala que, al menos en términos generales, la producción agrícola no se ha visto dramáticamente afectada por cambio climático alguno, todo lo contrario, hasta el año 2006 la producción en la provincia de Anta se incrementó. Por lo tanto, podemos afirmar que el impacto del llamado "calentamiento global" no ha afectado dramáticamente a la población de Anta en general. Debemos sí, hacer la salvedad de que los posibles impactos por las variaciones climáticas pueden ser diversas en las diferentes zonas de la Sierra Sur, pero de acuerdo a lo observado hasta el momento no se han producido problemas graves en la zona, al menos no problemas que no puedan ser enfrentados por los métodos que los campesinos conocen.

\section{La percepción de las ONG que trabajan en el sur andino sobre el cambio climático}

Una ONG que está presente en el sur andino es OXFAM. OXFAM organiza en todo el mundo "audiencias climáticas", que describe de la forma siguiente:

La vida de las personas ya está siendo afectada de manera directa por los efectos negativos del Cambio climático. Las Audiencias Climáticas son eventos públicos que se realizan por todo el mundo y que buscan hacer oír la voz de los más afectados. De aldeas locales hasta proyección a gran escala, el proyecto de las Audiencias Climáticas traslada las voces de los más afectados por los devastadores impactos

5 En: Plan Vial Participativo de la provincia de Anta. abril del 2006. http://www. proviasdes.gob.pe/Unidades/planes_viales $\% 5$ Ccusco $\% 5$ Canta.pdf 
del cambio climático directamente a todos aquellos que toman las decisiones y que tienen la oportunidad real de hacer algo al respecto ${ }^{6}$.

Ya en esta cita queda patente que OXFAM parte de la idea de efectos negativos del cambio climático y que los campesinos que reúne en las Audiencias Climáticas expresan la "voz de los más afectados por los devastadores impactos del cambio climático". Nuestras indagaciones entre personas que han trabajado en tales audiencias nos mostraron que efectivamente en tales audiencias se recoge la información de campesinos sobre la temática. En el Centro Bartolomé de las Casas por ejemplo se nos informó que había dos proyectos en marcha que recogerían información sobre el cambio climático en el contexto de los campesinos. Es decir, las reuniones efectivamente eran conducidas a la recolección de información en el sentido que esta diera cuenta de los cambios en las condiciones de vida de los agricultores y pastores con la connotación de cambios dañinos. En nuestra indagación en la Pampa de Anta, sin embargo, surgía una información que resultaba menos catastrófica, que arrojaba como resultado que los campesinos sí se daban cuenta de que vivían una época de variación climática pero su experiencia y los recursos en su sistema de manejo agrícola mostraban que ellos no percibían estos cambios como completamente excepcionales. En cambio, sabían reaccionar a las variaciones al interior de un sistema agrícola que estaba preparado para variaciones tanto en las precipitaciones pluviales como en los cambios de temperatura media. Para ellos, lejos de reflejar la opinión apriorística de OXFAM como de otras ONG, hubo cambios a los cuales podían responder adecuadamente y los cambios observados por ellos en una serie de aspectos les resultaban beneficiosos.

Desgraciadamente no tuvimos acceso a la información recogida por las ONG, ya que los estudios todavía no habían culminado en resultados publicables o reportables. Pero por el método de recolección es de esperar que los "estudios" efectivamente reflejarán los resultados anticipados por las $\mathrm{ONG}$, es decir tendrán una visión más bien catastrófica pues parten de la idea de lo negativo del cambio climático y que este es ocasionado por efecto de las industrias de países de "Primer Mundo".

La misma financiadora de ONG informa por ejemplo sobre Bolivia de la siguiente manera ${ }^{7}$ :

\section{Los bolivianos luchan para adaptarse sin financiación}

El informe, Cambio Climático, Adaptación y Pobreza en Bolivia, muestra cómo el deshielo de los glaciares, los desastres naturales, las enfermedades, los incendios forestales y los patrones del clima

\footnotetext{
6 En: http://www.oxfam.org/es/campaigns/climatechange/audiencias-climaticas En: http://www.oxfam.org/es/pressroom/pressrelease/2009-11-04/boliviagolpeada-cambio-climatico
} 
erráticos podrían devastar un país que tiene poca responsabilidad de la crisis climática. En el 2000 Bolivia fue responsable del $0.35 \%$ de las emisiones globales de gases de efecto invernadero, comparado con el $16 \%$ de los EEUU y el $12 \%$ de la UE.

También muestra cómo las comunidades bolivianas están luchando para adaptarse al clima cambiante a pesar de no contar con apoyo financiero internacional. Por ejemplo, comunidades pobres en Beni están recuperando una práctica ancestral de terrenos de cultivo elevados, llamados camellones, para proteger sus cultivos de las inundaciones. Los países ricos tienen todavía que comprometerse con unos 50.000 millones de dólares de dinero extra al año, que es lo que necesitan los países pobres para desarrollar proyectos como este”.

Es interesante en este caso, a pesar del tono catastrófico de base, que la noticia hace mención de los "camellones", que no son otra cosa que los "waru waru" mencionados para las tierras altiplánicas como un método antiguo para manejar las condiciones hídricas del suelo. Sin embargo, en esta nota de Oxfam se menciona la recuperación de estos waru waru como una técnica ancestral, si bien los informes etnohistóricos sobre esta zona muestran que efectivamente es un método antiguo de la agricultura altiplánica para manejar las condiciones hídricas cambiantes en esta zona, esta se sigue utilizando actualmente aunque en menor medida. Es decir, no es un recurso desesperado que habría que rescatar, sino una técnica habitual de los pobladores para manejar los cambios periódicos de las condiciones hídricas cambiantes de la zona.

Por otro lado, siguiendo la lógica de que los principales responsables del calentamiento global son los países industrializados, se ha acuñado un nuevo término que apela a que éstos asuman su responsabilidad ante tales acciones: Justicia climática. Este término ahora es usado ampliamente en los discursos de las organizaciones ambientalistas y por las personas que están involucradas en sus actividades, como los mismos campesinos que fueron partícipes de las audiencias climáticas organizadas por el MOCICC (Movimiento ciudadano frente al cambio climático), institución que agrupa a diferentes organizaciones sociales que abordan la temática del cambio climático. Con este término aluden a la indemnización que reclaman para los países pobres afectados por el calentamiento global por parte de los países industrializados. Los campesinos siempre son vistos como víctimas en estos discursos que no profundizan en su capacidad de acción ante los cambios que ellos enfrentan en sus actividades agrícolas, a pesar que el discurso "ongístico" está plagado de frases que proponen "la recuperación y promoción de técnicas ancestrales", estas organizaciones enfatizan en este término de Justicia climática y en la solución de esta supuesta problemática a través de la implantación de políticas públicas de medio ambiente. Esto es observado por ejemplo en el siguiente documento publicado por el MOCICC: 


\section{Pronunciamiento del Cusco \\ Audicencia pública de cambio climático}

Representantes de las organizaciones sociales, comunidades campesinas, instituciones públicas y de la sociedad civil de la Región Cusco, reunidos en la Audiencia Climática Regional, desarrollada en la ciudad del Cusco, el día 28 de agosto del 2009, nos pronunciamos en los siguientes términos:

Conscientes de los impactos nocivos que el cambio climático viene generando en nuestras vidas, en nuestros medios de vida, en la disponibilidad de nuestras aguas y en nuestra seguridad alimentaria. Frente a la agresión brutal que sufre nuestra PACHAMAMA, sustento de vida de nuestras generaciones pasadas, presentes y futuras, como consecuencia de un modelo de explotación industrial de la naturaleza de forma irracional, agresiva e inmisericorde, principalmente por los países más ricos y desarrollados como EEUU, China, Unión Europea y Rusia que en conjunto son responsables de cerca del $50 \%$ de la emisión de gases de efecto invernadero, que asola y contamina principalmente a países pobres como el nuestro, tal es así que el Perú es uno de los tres más afectados a nivel mundial y nuestro "Qosqo" una de las 10 regiones más vulnerables.

Frente a estas evidencias nos pronunciamos:

1.- Que los países industrializados y empresas transnacionales, responsables del calentamiento global y la contaminación ambiental mundial, indemnicen económica, social y moralmente a los pueblos victimas del daño ambiental irreversible generado.

2.- Que el Estado central peruano, asuma un rol más efectivo y protagónico en el propósito de exigir el cumplimento de los acuerdos y tratados internacionales como el protocolo de Kyoto y los nuevos por suscribirse, en resguardo de nuestra supervivencia humana.

3.- Que el Estado peruano, en sus tres niveles, implemente políticas de protección ambiental y desarrollo sostenible, formuladas participativamente, que incorporen y acojan los conocimientos ancestrales de nuestros pueblos andinos y amazónicos en referencia a la buena gestión de los recursos naturales como el agua, suelos, cobertura vegetal y agro biodiversidad.

4.- Que se revise el marco jurídico nacional relacionado a la explotación de los recursos naturales, que viene generando formas irracionales de extracción de nuestros bosques, aguas y tierras, generando mayor contaminación ambiental en nuestra región.

5.- Llamamos a nuestro gobierno regional y nuestros gobiernos locales, a implementar políticas públicas, además de medidas y acciones de adaptación frente al cambio climático, articulados en un 
plan regional y nacional en cumplimiento irrestricto a las recomendaciones de los acuerdos y convenios internacionales de protección del medio ambiente.

6.- Invocamos a nuestros hermanos, hermanas y conciudadanos de toda nuestra región a asumir un rol consciente y vigilante en el cuidado y protección del medio ambiente y a desarrollar buenas prácticas de adaptación y mitigación frente a los efectos negativos que el calentamiento global viene generando en nuestras vidas.

Qosco, 28 de agosto del 2009

También en este texto resulta visible que la tónica general es la repetición de los discursos provenientes de Europa y EEUU sobre las probables consecuencias catastróficas del calentamiento global. Si bien el informe hace referencia a que el Estado y las ONG asuman roles protagónicos en la defensa de las condiciones de vida queda patente que no hay una indagación previa entre la población campesina sobre sus recursos técnicos y de conocimiento y sobre las situaciones efectivas que se dan en las diversas regiones con las variaciones climáticas de los últimos decenios. En cierto grado se podría colegir del discurso que ellos se presentan como una instancia "necesaria" para mediar entre las instituciones a nivel global y nacional para procurar el bien del campesinado. Si bien se legitiman, o se intenta hacerlo, estos discursos con la presentación de testimonios de campesinos, es notorio que muchos de ellos al pronunciarse repiten discursos y vocabularios propios de las ONG ambientalistas que son quienes convocan estos espacios. Las declaraciones de los campesinos, en ese sentido, no parecen muy propias, sino adecuadas a las lógicas de estas instituciones que prácticamente parecen haberles enseñado sobre la problemática en cuestión. Así, por ejemplo tenemos el testimonio de un campesino de la comunidad de Mantoclla en $A n t a^{8}$ :

\section{¿Se ha logrado que la gente de la ciudad tenga más sensibilidad con este problema?}

Bueno, una parte de la gente se ha dado cuenta de qué está pasando con el cambio climático, ahora poco a poco se está contagiando esa conciencia. Antes de estas audiencias nadie nos decía nada de qué es esto, no se sabía de dónde venían esas consecuencias. Si no fuera por el MOCICC, mi voz, la voz de mi compañero y otros compañeros no serían escuchados a través de emisoras, canales. Ahora tenemos posibilidad para siquiera hablar unas cuantas palabras y decir lo que los campesinos estamos sufriendo a consecuencia del cambio climático. (El énfasis es mío)

8 En: "Hasta los sapitos han desaparecido". Por Paul E. Maquet. Alerta Perú, año 2, número 12. Noviembre del 2009. Pág. 12. 
Además, debemos señalar que si bien en estas audiencias climáticas se presentan los testimonios de los campesinos, pretendiendo ser representativos de los supuestos graves problemas que ellos enfrentan ante el "calentamiento global", notamos que en las diferentes noticias y pronunciamientos de las audiencias climáticas se repite el testimonio de un campesino cusqueño del distrito de Ocongate, zona cercana a las alturas del nevado Ausangate, lugar que efectivamente se ve afectado por la deglaciación de este nevado.

Cayetano Huanca, Presidente de Defensa de Recursos Naturales y Medio Ambiente de Ocongate (Cusco) habló de la reducción de los nevados. "Nosotros vivimos al pie del Ausangate, donde nace el agua dulce. Antes había nevados, qué hermoso era el Ausangate. Ahora hay una desglaciación, el agua está escasa, están disminuyendo los bofedales, los puquios están secándose".

"Cuando quiere llueve, cuando no quiere no. Hay escasez y exceso de lluvias, entonces ¿con qué confianza mis hermanos van a hacer la agricultura?", se preguntó Cayetano. "Los campesinos decimos, ¿ipor qué pagamos los platos rotos, qué culpa tenemos nosotros? Y los países grandes industrializados ¿qué están pensando? Por lo menos que nos indemnicen", concluyóp.

Sin embargo; se toma este testimonio como paradigmático y representativo de la realidad de los campesinos cusqueños, cuando en realidad lo que hemos podido observar y conocer mediante conversaciones con campesinos de otras zonas de Cusco, las percepciones y acciones de los campesinos son muy diversas en tanto son también diversas sus experiencias.

Juzgando por la información recogida en la Pampa de Anta se podría dudar de esta lógica. Parecería que hasta el momento los campesinos mismos con la tecnología adaptada desde hace muchos milenios a cambios climáticos en los Andes tienen los recursos técnicos y cognitivos para enfrentar el cambio climático tal como se está dando efectivamente en la zona observada. Por lo tanto, habría que preguntarse si los promotores de las ONG son lo que pretenden ser. Juzgando por los pocos ejemplos que hemos podido ofrecer parecería más bien que las ONG tienen una necesidad de legitimar su presencia en la sociedad con discursos que reducen las posibilidades de las cuales dispone la población campesina. Como es probable que busquen un financiamiento desde el exterior resulta igualmente probable que no indagan bien en los recursos culturales de los cuales disponen las poblaciones andinas de las regiones diversas para adaptarse a cambios que efectivamente se dan con las variaciones climáticas, cualesquiera que sean las causas de ellas.

\footnotetext{
9 En: http://www.oxfam.org/es/campaigns/climatechange/audiencia-nacional-decambio-climatico-lima-peru
} 
Por otro lado, también a nivel local conjuntamente con las autoridades municipales se promueven y realizan actividades para aplacar las consecuencias de las variaciones climáticas que se presentan en la zona, como son la siembra de árboles nativos, noticia a la cual tuvimos acceso por su publicación en Internet:

"La siembra de estos árboles permitirán la cosecha y siembra de agua, y, por ende, la recuperación de ríos, pues las plantas nativas son captadoras de agua y nutren el suelo", explicó (el alcalde provincial de Anta) al indicar que los árboles se instalarán en los ocho distritos de Anta.

En la provincia de Anta — dijo- ya se sienten los efectos del cambio climático, "y estos se traducen en que prácticamente han desaparecido los cuatro nevados que teníamos". ${ }^{10}$

Sin embargo, observamos también por parte del alcalde el uso del término cambio climático como algo que afecta negativa y ampliamente las actividades campesinas, siendo esto una muestra de cómo han ido calando los discursos sobre este tema en la población, especialmente en aquellas personas que forman parte de instituciones u organizaciones sociales. En este caso el alcalde de Anta, quien también forma parte de REMURPE (Red de municipalidades rurales del Perú), tiene frecuente contacto con diversas organizaciones que manejan la temática, además tiene la experiencia misma de gestión ambiental ya que es conocido su trabajo promotor de gestión sostenible a través de iniciativas de su provincia en manejo de desechos cuidando de esta forma el medioambiente de su zona. Estas iniciativas le han dado el nombre a Anta de "pueblo ecológico". Es decir, con esto último se muestra que existen iniciativas propias locales de los campesinos de la zona conjuntamente con sus autoridades para hacer frente a las variaciones del clima que afecta en distinta medida a las diversas zonas de la provincia.

\section{Conclusiones}

A través de las distintas fuentes de información a las cuales tuvimos acceso podemos concluir que el llamado cambio climático afecta en distinta medida a la población campesina de Anta, algo que no necesariamente se expresa en un impacto negativo de tales variaciones sobre las actividades agrícolas. Asimismo, hemos observado que el llamado cambio climático no es algo que en amplia medida a los campesinos se les presente como excepcional y catastrófico ya que ellos a lo largo del tiempo han experimentado variaciones climáticas a las que han hecho y hacen frente con estrategias y

10 Sembrarán dos millones de árboles nativos en provincia cusqueña de Anta para enfrentar cambio climático. Anta, 21 de octubre. En: http://www.andina.com.pe/ espanol/Noticia.aspx?id $=\mathrm{dKojahFFvDo}=$ 
técnicas de reducción de riesgos climáticos que son conocidos desde milenios atrás, tal como la literatura sobre agricultura campesina nos ha mostrado. Entonces, estas variaciones son algo constante en la vida campesina, si bien se puede afirmar que en los últimos años las variaciones climáticas han sido más fuertes que tiempos atrás para campesinos de algunas zonas.

Sin embargo, apreciamos que los testimonios de los campesinos que manifiestan un fuerte impacto negativo sobre su vida y actividades agrícolas, se ven fuertemente influenciados por los discursos de las ONG que toman a priori la existencia de un cambio climático dramático causado por los países industrializados a los cuales se les demanda la indemnización para los campesinos pobres a los cuales estas organizaciones dicen servir. Estas ONG, no obstante, dan por sentado tales aseveraciones a pesar de que científicamente no se ha comprobado fehacientemente el origen de estos cambios, pues sigue en pie la discusión sobre esta temática. Los fines de las ONG, como hemos visto, es legitimar sus discursos traídos de realidades externas a la de los campesinos de la Sierra Sur a través de la presentación de testimonios de algunos casos que no son en mayor medida representativos de la diversidad de realidades campesinas de nuestro país.

Finalmente, creemos que para abordar un tema tan complejo como se presenta el cambio climático se debe tener mucho cuidado al generalizar las experiencias campesinas y sobre todo se debe conocer las particularidades de estas experiencias en lo referente a las percepciones y acciones de los campesinos frente a este tema, pues asumiendo verdades a priori sobre el origen e impacto del "calentamiento global" y necesidades campesinas en torno a ello no se pueden lograr consensos ni avances en la superación de la supuesta problemática. Además, se reproducirían las tradicionales relaciones opresor-oprimido que han marcado nuestra historia con el llamado Primer mundo, Primer mundo que como siempre sería el encargado de "salvarnos" de esta situación.

\section{BIBLIOGRAFÍA}

ATLAS DEL PERÚ, Proyecto especial

1989 Atlas del Perú. Lima: Instituto Geográfico Nacional.

BBC

2009 The arguments made by climate change skeptics. En: http://news. bbc.co.uk/2/hi/science/nature/8376286.stm

CAMINO, Alejandro; RECHARTE, Jorge y BIDEGARAY, Pedro

kawsayninkupaq rurasqankunaqa; pp. 169-194. México, D. F.: UNAM.

EARLS, John

2009 Manejo de Cuencas y Cambio Climático. PUCP. 
FLORES OCHOA, Jorge; FLORES, Percy y ROZAS, Washington

1996 Un (re-) descubrimiento reciente: la agricultura en las lagunas temporales (qocha) en el Altiplano, en Pierre Morlon (ed.), Comprender la agricultura campesina en los Andes Centrales: Perú - Bolivia; pp. 86-117. Lima: IFEA y CBC

GARAYCOCHEA, Ignacio; RAMOS, Claudio y MORLON, Pierre

1996 La arqueología aplicada al desarrollo: La reconstrucción de camellones precolombinos en el Altiplano, en Pierre Morlon (ed.), Comprender la agricultura campesina en los Andes Centrales. Perú - Bolivia; pp. 234-247. Lima: IFEA y CBC.

GOLTE, Jürgen

1980 La racionalidad de la organización andina. Lima: Instituto de Estudios Peruanos.

HUDSON, Paul

2009 What happened to global warmig? BBC News. En: http://news.bbc. co.uk/2/hi/8299079.stm, 9 de octuubre.

MARCELLESI, Florent

2008 "Ecología política: gémesis, teoría y práxis de la ideología verde”, en, Cuadernos Baekeasž pp. 1-15. Bilbao: Bakeasz.

MAQUET, Paul

2009 "Hasta los sapitos han desaparecido", en Alerta Perú, año 2 número 12. Pág. 12

MORLON, Pierre

1996 "Reduccióndelos riesgos climáticos por medio de acondicionamientos: el ejemplo de las heladas en el Altiplano", en Pierre Morlon (ed.), Comprender la agricultura campesina en los Andes Centrales. Perú-Bolivia; pp. 38-83. Lima: IFEA y CBC.

MUNICIPALIDAD PROVINCIAL DE ANTA

2006 Plan Vial Participativo de la provincia de Anta. En: http://www. proviasdes.gob.pe/Unidades/planes_viales $\% 5$ Ccusco $\% 5$ Canta.pdf

SMITH, Clifford T.; DENEVAN William M. y HAMILTON, Patrick

1981 "Antiguos campos de camellones en la región del lago Titicaca", en Heather y Ana María Soldi Lechtman (ed.), La tecnología en el mundo andino - Runakunap kawsayninkupaq rurasqankunaqa; pp. 25-50. México, D. F.: UNAM.

OXFAM Internacional

2009 Pronunciamiento del Cusco: Audiencia pública de cambio climático. En: $\quad$ http://www.oxfam.org/es/campaigns/climatechange/ audiencia-nacional-de-cambio-climatico-lima-peru 